\title{
Corrigendum: Glycan complexity dictates microbial resource allocation in the large intestine
}

Artur Rogowski, Jonathon A. Briggs, Jennifer C. Mortimer, Theodora Tryfona, Nicolas Terrapon, Elisabeth C. Lowe, Arnaud Baslé, Carl Morland, Alison M. Day, Hongjun Zheng, Theresa E. Rogers, Paul Thompson, Alastair R. Hawkins, Madhav P. Yadav, Bernard Henrissat, Eric C. Martens, Paul Dupree, Harry J. Gilbert \& David N. Bolam

Nature Communications 6:7481 doi: 10.1038/ncomms8481 (2015); Published 26 Jun 2015; Updated 5 Feb 2016

The financial support for the work described in this Article was not fully acknowledged. The Acknowledgements should have included the following:

This work was supported in part by a grant to H.J.G., B.H. and N.T. (European Union's Seventh Framework Program (FP/2007/2013)/European Research Council (ERC) Grant Agreement 322820).

(c) This work is licensed under a Creative Commons Attribution 4.0 International License. The images or other third party material in this article are included in the article's Creative Commons license, unless indicated otherwise in the credit line; if the material is not included under the Creative Commons license, users will need to obtain permission from the license holder to reproduce the material. To view a copy of this license, visit http://creativecommons.org/licenses/by/4.0/ 